\title{
Selenium and Tellurium Chemistry: Historical Background
}

\author{
João V. Comasseto* \\ Instituto de Química, Universidade de São Paulo, Av. Prof. Lineu Prestes, 748, \\ 05508-000 São Paulo-SP, Brazil
}

\begin{abstract}
Neste artigo apresentamos um apanhado geral sobre a história da química do selênio e do telúrio no Brasil e no mundo.

In this paper we present a general survey on the history of the selenium and tellurium chemistry in Brazil and worldwide.
\end{abstract}

Keywords: organotellurides, organoselenides, tellurides, selenides, selenium, tellurium

\section{Historical Background}

The $3^{\text {rd }}$ Brazilian Meeting on the Chemistry of Selenium and Tellurium was held in Florianopolis, SC in 2010. These meetings began in 2006 as an initiative of the professors from the Universidade Federal de Santa Maria, RS, who dedicated their research efforts to selenium and tellurium chemistry. The $1^{\text {st }}$ meeting was coordinated by Prof. Enesto Shultz Lang and took place in Bento Gonçalves-RS. The $2^{\text {nd }}$ meeting, coordinated by Prof. Hélio Stefani, happened in 2008 in Campos de Jordão-SP.

In view of the Brazilian chemical community origins, this event represents an important milestone to the Brazilian chemists dedicated to this field. The oldest Brazilian university, Universidade de São Paulo, was founded in 1934. Several great European scientists accepted the invitation to join the new university. One of them was Professor Heinrich Rheinboldt, from Bonn University, who had an academic and familiar history linked to some of the most important chemists of the $19^{\text {th }}$ century and the beginning of the $20^{\text {th }}$. In the beginning of his career, he was an assistant of Paul Pfeiffer, who was Alfred Werner's student. He was Heinrich Caro's grandson, one of the pioneers of the German chemistry industry. With Rheinboldt's arrival in Brazil, the chemistry in this country was then born. He chose the selenium and tellurium chemistry as the subject of his research in his new country, mainly because this branch of chemistry was not extensively explored in the rest of the world at that time. The first years of the new

*e-mail: jvcomass@iq.usp.br university, as well as those of Rheinboldt's laboratory, were difficult, especially in view of the lack of scientific tradition in Brazil. However, Rheinboldt and his team created a new branch of chemistry while he was alive. In the year of his death he published a chapter of Houben Weyl devoted to selenium and tellurium, in which he reported, for the first time, the accumulated knowledge on this field. ${ }^{1}$ Rheinboldt's school had a deep influence in the development of chemistry in Brazil, and many chemistry departments can trace back their origins to Rheinboldt's group. From Rheinboldt's students, only Nicola Petragnani, who finished his Ph.D. thesis after the death of his supervisor, continued working with selenium and tellurium chemistry, initially, as Prof. Marcelo de Moura Campos' assistant. During the 1960s Prof. Campos and Prof. Petragnani worked intensely on selenium and tellurium organic chemistry. Among the several reactions developed by Prof. Campos and Prof. Petragnani at that time, we mention the selenium and tellurium promoted cyclization of unsaturated substrates. ${ }^{2}$ This fact is very often omitted in texts dedicated to organoselenium chemistry, which report the discovery of this reaction as occurring about fifteen years later. Recently, this reaction has had a revival due to the work of several groups around the world. ${ }^{3}$

\subsection{The $1970 \mathrm{~s}$}

Early in the 1970s, Carl Djerassi coordinated a joint program between the National Academy of Sciences (NASUSA) and the Brazilian Research Council (CNPq). ${ }^{4}$ This program was aimed at updating chemistry in Brazil. Prof. 
Campos' laboratory hosted the organic synthesis program. Upon his retirement in 1974, Prof. Petragani became the head of the program, which consisted of periodical visits of top American synthetic organic chemists to the Institute of Chemistry of the University of São Paulo, for seminars and scientific meetings. Young synthetic organic chemists came to stay for longer periods, typically for two years, to teach Brazilian students modern methods and techniques in organic synthesis. This program deeply influenced all chemistry areas in Brazil. The participating Brazilian laboratories received an enormous input of new scientific knowledge. A new mentality as to how to do science was introduced. ${ }^{5}$

Regarding the selenium and tellurium organic chemistry, the program led to a decrease in the pace of work. The "American staff" when were not hostile to this type of chemistry, ignored it completely. Among the students who continued in the academy in Brazil, only I worked with chemistry of selenium and tellurium at Prof. N. Petragnani's laboratory. For this reason I was nicknamed "The Alchemist" by my colleagues involved in the "American" projects, in view of the quite archaic experimental methods of work used to do chemistry of tellurium in Sao Paulo at the time, inherited from the time when Rheinboldt came to Brazil. When I initiated my independent research work in 1980, I tried to associate the selenium and tellurium chemistry with the "modern" organic synthesis I had learned during my $\mathrm{PhD}$ and postdoc programs, what resulted in the several topics on the organic selenium and tellurium chemistry explored by my students during the 30 years to come.

\subsection{The $1980 \mathrm{~s}$}

The year 1980 was a decisiving year for the consolidation of this line of work in Brazil. In June of that year I returned from my post-doc program at Prof. E. Vogel's laboratory at the University of Cologne. Like any young man beginning his scientific career, I was faced with the dilemma: which direction should I give to my scientific work? There was an enormous pressure on me to adopt the line of work brought about by the CNPq / NAS program, or to follow my postdoctorate line, and, besides that, there were also several lines of work which I had been in contact with in Europe. To continue the line of work in selenium and tellurium was considered by all, the worst option not to mention the "lack of originality" of continuing to work in the same area of my PhD. However, a paper published by H. C. Brown in early 1979 gave support to my decision to invest in this area, especially in the chemistry of tellurium, with little or no international competition, which was a great appeal in view of the precarious conditions for research materials at that time in Brazil. Brown concludes that article with the following words: "It is evident from this review that the senior author provides an unambiguous example of the oft criticized worker who continues extending his PhD thesis for many, many years-forty years in this case, with the end not yet in sight. However, it has been a fruitful journey. There is an intense pleasure in observing a field of knowledge and practice develop from almost nothing into a major area ..." At the end of 1979 H. C. Brown won the Nobel prize for his work on chemistry of Boron. Between Brown's and my colleagues' opinions, I chose the first option!

Upon returning to São Carlos in 1980, I met several colleagues and students eager to do chemistry, among them Antonio Braga, guest editor of this special issue. After a year and a half working in São Carlos, Braga as an undergraduate student of J. Tércio Ferreira, we transferred to the IQ-USP, Braga as my graduate student. Shortly, other students from São Carlos, Santa Maria, as well as from other cities in Brazil came to São Paulo, and all got together at the laboratory. Throughout the 1980s the group of about seven people laid the foundation of much of the chemistry reported in this special issue. Towards the end of the 1980s they went to other universities as professors, many of them went to the Federal University of Santa Maria. Everyone continued working with chemistry of selenium and tellurium, but without any ties with my lab. Gradually, these people started creating their own fields of work, in some cases quite different from that of the ex-coach. They supervised a large number of masters and doctors, who in turn settled in several universities, mainly in Rio Grande do Sul. Two of these new doctors, alumni of A. L. Braga, were recently absorbed as lecturers at the University of São Paulo. Over these 30 years we recorded 133 master's dissertations, more than 90 doctoral thesis and 20 postdoctoral stages guided by me, by my former advisees and by their own former advisees. A total of more than 600 papers were published by members of the group to date. Besides this group, other Brazilian laboratories dedicated to the chemistry of selenium, especially in the area of biochemistry, and have contributed to this special issue as well.

\section{Selenium}

Considering the chemical element selenium in a broader context, we emphasize that it was discovered in 1817 by Berzelius in deposits formed in chambers of lead at his sulfuric acid plant at Gripsholm, Sweden. Berzelius gave the name selenium to the new element 
in honor of Selene, Greek goddess of the moon. Arne Fredga, pioneer of modern organic chemistry of selenium and for several years chairman of the Nobel Committee tells us: "Berzelius realized at once the similarity between sulfur and selenium. For about a century, organoselenium chemistry was a neglected field. In the 1920s the entire literature consisted of about 200 papers. Now and then the sulfur chemist made a casual digression into the selenium domain, prepared a few compounds, and found them similar to the sulfur analogs, though less stable. The sudden appearance of red smears instead of the expected product was (and still is) a common and disconcerting experience. The highly unpleasant odor of many selenium compounds can also be discouraging. Organosulfur compounds have a bad reputation in this respect, but the selenium analogs are worse."

These comments made in 1971 show us that the special features of the preparative organic chemistry of selenium were still to be fully mastered at that time when I myself am a witness of the difficulty of manipulating organic selenium compounds in the laboratory due to its bad smell, and to reproduce reported results, in view of the little knowledge of organic chemists of that time on the chemistry of this element. My first contact with the chemistry of selenium happened in 1973, two years after the comments of Fredga above mentioned.

Another problem associated with selenium compounds is its bad reputation as highly detrimental to health. It is still Fredga who tells us: "For many years selenium was regarded as rather uninteresting from the biological point of view. Around 1930, however, attention was drawn to the toxic properties of this element, which is very widespread, although its overall concentration in the earth's crust is only $10^{-5 \%}$. It was discovered that selenium, if present in the soil even in minute amounts, is taken up by the vegetation and may cause damage to animals grazing on the toxic plants. Alkali disease and blind staggers, diseases of livestock known for a long time, could now be attributed to chronic selenium poisoning. Certain plant species were found to accumulate selenium in spectacular quantities. Some of them are dependent on selenium for normal growth and never occur on selenium-free soils. Although such indicator plants are highly toxic to most animals, they are capable of supporting parasites, insect larvae with very high selenium tolerance. The relationship between selenium and vegetation presents many interesting problems. In the 1930's it was also shown that the feeding of selenium-containing cereals to hens may cause malformations, monstrosities, or death in the chickens. This was one of the first cases in which a chemical agent was found to affect the embryo in a detrimental way without apparent injury to the mother."
After these discoveries, some incidents have become folklore attributed to selenium. According to Martin "The ingestion of seleniferous plants by livestock, with the consequent development of well-defined disorders, has been a problem to stockmen and farmers for centuries. Perhaps the first report describing a disease syndrome resulting from the ingestion of seleniferous plants was that of Marco Polo during his famous travels to the Orient. In 1295 Marco Polo recorded in his journal that beasts of burden were afflicted by a peculiar disorder when they were fed on a particular plant which grew in western China near the border of Turkestan and Tibet. One of the symptoms he described was that the hoofs of the affected animals dropped off. Only recently has it become evident that this disorder is characteristic of a type of chronic selenosis." 8

All this contributed and continues to contribute to keep organic chemists away from selenium compounds.

Finally, in 1957 something positive about selenium was discovered. Schwartz and Foltz found evidence that selenium is an essential trace element in the animal diet. ${ }^{9}$ The absence of a minimum amount of selenium in the diet causes severe disturbances in animals and humans. ${ }^{10}$ The explanation was that selenium was found in the active site of glutathione peroxidase of mammals as the $21^{\text {st }}$ amino acid, selenocisteine. ${ }^{11}$ The importance of glutathione peroxidases is well known: ${ }^{12}$ glutathione peroxidase GPX-1 is involved in removing peroxides and serves as part of the antioxidant defense system of organisms..$^{10}$ These findings attracted the attention of the scientific community to the chemistry of selenium. Currently there is intense activity in the area involving selenium compounds and biological systems. ${ }^{13,14}$

\section{Tellurium}

Regarding tellurium, the history of the element is older than that of selenium. Tellurium was discovered by von Reichenstein in 1782 in minerals existing in the gold districts of Transilvania. ${ }^{14}$ Its name comes from the Latin "tellus", meaning earth. The preparation of the first organotellurium compound, the volatile and malodorous diethyl telluride, was described by Wöhler in 1840 . About this compound Wöhler wrote, “. ... and because its highly persistent and obnoxious smell is connected to unpleasantness, which one would not like to endure a second time...". ${ }^{15}$ Heeren also stated: "The smell is so persistent, that one has to avoid social life for several months in order not to molest other people."16 These statements were probably responsible for the long hibernation of the organic chemistry of tellurium. Only about 50 papers were published on tellurium chemistry between 1910 and 1950. It was only about a 
century after Wöhler's paper that the first comprehensive account of the organic chemistry of this element appeared in the literature as part of the already mentioned chapter in Houben-Weyl. ${ }^{1}$ Rheinboldt's group showed that several classes of organic tellurium compounds were solid, and most of them were almost odorless, especially the aromatic ones. As already commented, Petragnani, Rheinboldt's last student, undertook extensive studies on the reactivity of inorganic and organic tellurium compounds towards several organic functional groups. This work, performed in the 1950s and 1960s, established the basis for the development of the organic chemistry of tellurium. In the last 30 years our group and several others around the world, developed methodologies to prepare several different kinds of organotellurium compounds. Nowadays we know that the bad smell of the organotelluro compounds is not a rule. ${ }^{17}$ The instability of the organotellurides to the light and air is better understood, ${ }^{18}$ and now chemists are able to manipulate them safely.

\section{Selenium and Tellurium Features}

At the beginning of the 1970s a number of facts occurred which allowed the selenium and tellurium chemistry to reach its current status. From 1971 on a series of conferences dedicated to the chemistry of selenium and tellurium started to be held. Dr. Wolfgang Günther was the first chairman of this series of conferences. ${ }^{19}$ At the same time Dr. Günther co-edited an excellent book on the organic chemistry of selenium, ${ }^{20}$ and Professors Irgolic and Zingaro published a very comprehensive book on the chemistry of tellurium. ${ }^{21}$ In 1970, an accidental discovery, the selenoxide syn elimination, ${ }^{22} \mathrm{drew}$ the attention from the organic chemistry community to the synthetic potential of the organoselenium compounds, and this branch of chemistry had an explosive growth during the following years. Various synthetic transformations using selenium were superior to the similar ones involving sulfur, making it clear that the chemistry of selenium is not a mere extension of the chemistry of sulfur. ${ }^{23}$ Following the success of the organic chemistry of selenium, the organic chemistry of tellurium also experienced a remarkable progress during the 1980s and 1990s, and in 1990, Irgolic published a volume of Houben-Weyl with 1000 pages covering all the organic chemistry of tellurium..$^{24}$ More recently a book by Petragnani was published, focusing on the synthetic application of tellurium reagents. ${ }^{25}$ Chemists realized that exploitation of the similarities between selenium and tellurium was of less interest than exploiting the differences between these two elements, and some laboratories began to take advantage of the unique features of organotellurium compounds. ${ }^{17}$

\section{Today}

Today, we can say that chemists were able to dominate the preparative chemistry of the organic compounds containing selenium and tellurium. We already know how to safely handle these compounds in the presence of air and light, and we know which ones are smelly and which ones are not. Methods of introducing these elements into organic molecules, avoiding the handling of smelly precursors, were developed. In the case of tellurium chemistry, the most important synthetic methods, make use of elemental tellurium as a starting point, generating the reactive intermediates in situ. ${ }^{17}$ In the case of the synthetic organic chemistry of selenium, non-volatile solid aromatic selenium reagents are generally used ${ }^{23}$ and the problems pointed out by Fredga we quoted above, no longer exist.

On the issue of security, several chemical reagents of daily use are toxic and some are poisonous. However, chemists have developed safe ways of handling these reagents. Obviously, whenever we can make use of a reagent that is completely secure, we will do it, instead of using other toxic or potentially toxic. In the specific case of selenium reagents, we already know quite clearly what problems they may cause and how to protect ourselves from them. In the case of tellurium reagents very little is known about its toxicology, ${ }^{13}$ and most of the assertions about their toxicity found in articles devoted to their synthetic application, are totally inappropriate. We are not aware of reports in the literature on poisoning by organic reagents of this element. Certainly, we need to clarify scientifically the implications of the manipulation of tellurium reagents by humans avoiding holding onto the folklore that has spread in the literature in this regard. We have shown that part of the folklore about the instability and the stench of tellurium compounds was false.

\section{Conclusion}

In conclusion, from a modest beginning some 40 years ago, the chemistry of tellurium and, to a greater extent, selenium evolved dramatically and may be regarded today as mature areas of chemistry, with numerous possibilities for research, in both areas, synthetic chemistry and biochemistry.

\section{Acknowledgments}

I thank my current and former advisees by the enthusiasm and dedication over these 30 years that contributed significantly to the present stage of development of the chemistry of selenium and tellurium. I am grateful for the financial support by the funding agencies FAPESP, CNPq, FINEP and CAPES. 


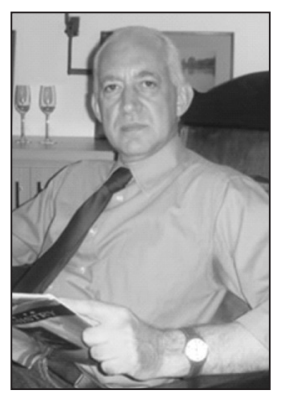

Prof. J. V. Comasseto was born in Santa Maria, RS. He has studied chemistry at the Universidade Federal de Santa Maria and obtained his $P h D$ at the Universidade de São Paulo, working with Nicola Petragnani. He spent one year at the University of Cologne as an Alexander von Humboldt post-doctoral fellow under the direction of E. Vogel. He has a "livre-docência" (corresponding to the German Habilitation) from the Instituto de Química of the Universidade de São Paulo. In 1976, he became an Assistant Professor at the Universidade Federal Rural do Rio de Janeiro. From 1977 to 1981 he was an Associate Professor of the Universidade Federal de São Carlos. Since 1981 he has been a Professor of the Instituto de Química of the Universidade de São Paulo, where he has been a Full Professor since 1992. His research interest in chemistry consists in the development of selenium and tellurium building blocks for organic synthesis.

\section{References}

1. Rheinboldt, H.; Selenium and Tellurium Chemistry, in Houben Weyl, Methoden der Organischen Chemie, vol. IX, Thieme Verlag: Stuttgart, Germany, 1955.

2. Campos, M. M.; Petragnani, N.; Chem. Ber. 1960, 93, 317.

3. Freundendahal, D. M.; Shahzad, S. A.; Wirth, T.; Eur. J. Org. Chem. 2009, 1649.

4. Chem. Eng. News 1970, 48(Jan 5), 30; Senise, P. Quím. Nova 2007, 30, 1397.

5. Spinola, A.; Quim. Nova 2007, 30, 1402.

6. Brown, H. C.; Krishnamurty, S.; Tetrahedron 1979, 35, 567.

7. Fredga, A. In Forward, in Organic Selenium Compounds: Their Chemistry and Biology; Klayman, D. L.; Günther, W. H. H., eds., Wiley Interscience: New York, p. vii, 1973.

8. Martin, J. L. In Selenium Compounds in Nature and Medicine, B - Selenium Assimilation in Animals, in Organic Selenium Compounds: Their Chemistry and Biology; Klayman, D. L.; Günther, W. H. H., eds., Chapter XIII, Wiley Interscience: New York, 1973.

9. Schwarz, K.; Foltz, C. M.; J. Am. Chem. Soc. 1957, 79, 3292.

10. Stapleton, S. R.; Cell. Mol. Life Sci. 2000, 57, 1823.
11. Hatfield, D. L.; Gladyshev, V. N.; Mol. Cell. Biol. 2002, 22, 3565 .

12. Arthur, J. R.; Cell. Mol. Life Sci. 2000, 57, 1825.

13. Nogueira, C. W.; Zeni, G. R.; Rocha, J. B. T.; Chem. Rev. 2004, 104, 6255; Mugesh, G.; Du Mont, W. W.; Sies, H.; Chem. Rev. 2001, 101, 2125; Alberto, E. E.; Nascimento, V.; Braga, A. L.; J. Braz. Chem. Soc. 2010, 11, 2032.

14. Cunha, R. L. O. R.; Gouvea, I. E.; Juliano, L.; An. Acad. Bras. Cienc. 2009, 81, 393.

15. Wöhler, F.; Liebigs Ann. Chem. 1852, 84, 69.

16. Heeren, M.; Chem. Zentralbl. 1861, 916.

17. Princival, J. L.; Dos Santos, A. A.; Comasseto, J. V.; J. Braz. Chem. Soc. 2010, 11, 2042.; Comasseto, J. V.; BarrientosAstigarraga, R. E.; Aldrichimica Acta 2000, 33, 66; Comasseto, J. V.; Clososki, G. C.; Cunha, R. L. O. R. In Tellurium, in Comprehensive Organometallic Chemistry III; Mingos, D. M. P.; Crabtree, R. H.; eds.; Elsevier: Amsterdam, vol. 9, PP. 587-648.

18. Ouchi, A.; Hyugano, T.; Liu, C.; Org. Lett. 2009,11, 4870.

19. Günther, W. H. H.; (ICCST Retrospective, Proceedings of the Eighth International Conference on the Chemistry of Selenium and Tellurium; Comasseto, J. V. ed.) Phosphorus, Sulfur, Silicon Relat. Elem. 2001, 171-172, 1.

20. Klayman, D. L.; Günther, W. H. H., eds.; Organic Selenium Compounds: Their Chemistry and Biology, Wiley Interscience, New York, 1973.

21. Irgolic, K. J.; Zingaro, R. A. In Tellurium, in Organometallic Reactions; Becker, E.; Tsutsui, M., eds., Wiley: New York, 1971.

22. Jones, D. N.; Mundy, D.; Whitehouse, R. D. J.; J. Chem. Soc., Chem. Commun. 1970, 86.

23. Back, T. G., ed.; Organoselenium Chemistry. A Practical Approach, Oxford University Press: Oxford, 1999.

24. Irgolic, K. C. In Organotellurium Compounds, Methods of Organic Chemistry (Houben-Weyl); Klamann, D., ed., vol. E12b, Georg Thieme Verlag: Stuttgart, 1990.

25. Petragnani, N.; Tellurium in Organic Synthesis, Academic Press: London, 1994; Petragnani, N.; Stefani, H. A.; Tellurium in Organic Synthesis; Second Edition: Second, Updated and Enlarged Edition (Best Synthetic Methods), Academic Press: London, 2007.

Submitted: May 17, 2010

Published online: August 5, 2010

FAPESP has sponsored the publication of this article. 